\title{
In-Hospital and Long-Term Outcomes of Beta-Blocker Treatment in Cocaine Users: A Systematic Review and Meta-analysis
}

\author{
Doosup Shin ${ }^{\mathrm{a}, \mathrm{c}}$, Eun Sun Lee ${ }^{\mathrm{b}}$, Chandrashekar Bohra ${ }^{\mathrm{a}}$, \\ Kullatham Kongpakpaisarn ${ }^{\mathrm{a}}$
}

\begin{abstract}
Background: Although $\beta$-blocker treatment is generally contraindicated in patients presenting with acute cocaine intoxication due to concern for unopposed $\alpha$-receptor stimulation, some studies have reported that $\beta$-blocker treatment did not increase adverse events in these patients. As this treatment is still controversial, we performed a meta-analysis of observational studies on this topic.
\end{abstract}

Methods: By searching three electronic databases (MEDLINE, EMBASE, and the Cochrane Library) from their inception to June 11, 2018, we identified eight observational studies with 2,048 patients who presented to hospital with cocaine-associated chest pain or after recent cocaine use. Outcomes of interest were myocardial necrosis or infarction (MI) and death during hospital stay or follow-up. Pooled relative risks (RRs) with $95 \%$ confidence intervals (CIs) were calculated by using a random-effects meta-analysis based on the DerSimonian-Laird method.

Results: Among patients presenting with cocaine-associated chest pain or recent cocaine use, there was no significant difference in inhospital all-cause mortality (RR, 0.59; 95\% CI, 0.24 - 1.47) and MI (RR, 1.24; 95\% CI, 0.74 - 2.06) between patients who did and did not receive $\beta$-blocker treatment during their hospital stay. During longterm follow-up (mean 2.6 years), there was no significant difference in all-cause mortality (RR, 0.79; 95\% CI, $0.44-1.41)$ and $\mathrm{MI}(\mathrm{RR}$, 0.96 ; $95 \%$ CI, $0.40-2.33$ ) between the two groups.

Conclusions: These results suggest that $\beta$-blocker treatment in patients presenting with cocaine intoxication may not be as harmful as originally believed. Further clinical studies are needed to investigate this topic.

Keywords: Beta-Blocker; Cocaine; Chest pain

Manuscript submitted January 7, 2019, accepted February 8, 2019

aDepartment of Internal Medicine, University of South Florida Morsani College of Medicine, Tampa, FL 33606, USA

bDepartment of Internal Medicine, Weiss Memorial Hospital, Chicago, IL 60640, USA

${ }^{\mathrm{c} C o r r e s p o n d i n g ~ A u t h o r: ~ D o o s u p ~ S h i n, ~ D e p a r t m e n t ~ o f ~ I n t e r n a l ~ M e d i c i n e, ~ U n i-~}$ versity of South Florida Morsani College of Medicine, 17 Davis Blvd., Suite 308, Tampa, FL 33606, USA. Email: doosup87@gmail.com

doi: https://doi.org/10.14740/cr831

\section{Introduction}

Cocaine is one of the most commonly used illicit drugs in the US. Each year, more than 400,000 of Americans present to the emergency department (ED) with cocaine-associated complications, which account for approximately $40 \%$ of all drugrelated visits to the ED [1-3]. More than half of these patients had cardiovascular toxicity, and $40 \%$ reported chest pain [3, 4]. Incidence of myocardial infarction (MI) among the patients presenting with cocaine-associated chest pain was reported to be $0.7-6 \%[5,6]$. Cocaine can cause chest pain or acute coronary syndrome (ACS) by increasing myocardial oxygen demand due to its sympathomimetic effect [7] and decreasing oxygen supply via coronary vasoconstriction [8].

Guidelines recommended treating patients presenting with cocaine-associated chest pain or ACS in the same manner as patients with traditional ACS, with few exceptions [3, 9]. Although $\beta$-blockers (BB) are a core component of treatment for patients with traditional ACS, they have been contraindicated in patients with signs of acute cocaine intoxication $[3,9,10]$. This is mainly due to concerns regarding coronary vasoconstriction and acute increase in blood pressure due to unopposed $\alpha$-receptor stimulation after BB treatment in cocaine toxicity $[3,9]$. However, there is much debate on this theory because it is largely based on animal studies, case reports, and small retrospective studies $[1,2,11-13]$. In fact, several observational studies have reported that BB treatment in the ED did not increase adverse events and mortality in patients with cocaineassociated chest pain [14-17]. Furthermore, some studies have demonstrated that $\mathrm{BB}$ treatment in these patients was associated with better long-term outcomes compared with those who did not receive it $[15,18]$. Because of ongoing controversy and inconsistency between studies, we conducted a meta-analysis on the association between BB treatment and clinical outcome in patients presenting with cocaine-associated chest pain.

\section{Materials and Methods}

\section{Search strategy and data sources}

This study was performed according to the PRISMA statement guidelines (Supplementary Table 1) (www.cardiolo- 


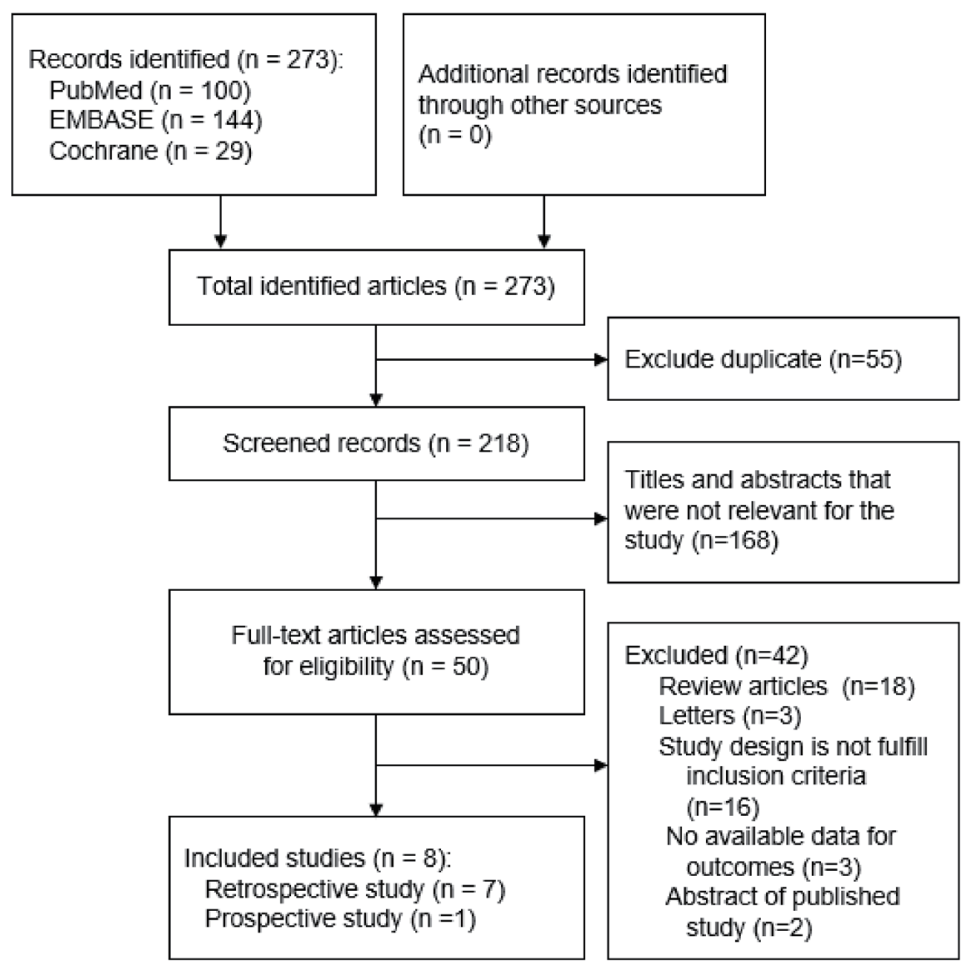

Figure 1. A flow diagram of identification of relevant studies.

gyres.org). Two authors (DS and ESL) independently searched MEDLINE, EMBASE, and the Cochrane Library from their inception until June 11, 2018, using the search terms "Betablocker(s)" or "Beta blocker(s)" and "Cocaine" with any restriction on language or publication status. The bibliographies of relevant articles were also reviewed to locate additional publications.

\section{Study selection}

We included observational studies that met the following predetermined criteria: 1) Included patients who presented with cocaine-associated chest pain or recent cocaine use; 2) Compared clinical outcomes between patients who received BB treatment during admission or at discharge and those who did not receive it; 3) Reported in-hospital or long-term outcomes including MI (or myocardial necrosis) or death. Both published studies and conference abstracts were considered to be included.

\section{Data extraction and quality assessment}

Study eligibility was evaluated by two independent investigators (DS and ESL) based on the predetermined selection criteria. Event numbers of death and MI (or myocardial necrosis) in patients with and without BB therapy were extracted from the studies. Disagreements between the two investigators were resolved by discussion with the other co-authors. The meth- odological quality of observational studies was assessed using the Newcastle-Ottawa Scale (NOS) [19].

\section{Statistical analyses}

For outcomes of interest, pooled relative risks (RRs) with $95 \%$ confidence intervals (CIs) were calculated using the number of events and nonevents extracted from individual studies. Estimates for in-hospital and long-term outcomes were pooled independently. A random-effects meta-analysis based on the DerSimonian-Laird method [20] was used due to functional inequality and difference in true effect sizes among the studies. Heterogeneity of results among the studies was assessed using the Higgins $\mathrm{I}^{2}$ value [21]. Publication bias was evaluated using Egger's test [22]. All statistical analyses were performed using Stata, version 12.1 (StataCorp, College Station, Texas, USA).

\section{Results}

\section{Identification of relevant studies}

Figure 1 displays a flow diagram of identification of relevant studies. A total of 273 articles were identified from the three databases and 218 studies were screened after excluding duplicates. After excluding 168 studies based on titles and abstracts, the full texts of 50 studies were reviewed. Eight cohort studies (seven retrospective [14-17, 23-25] and one prospective [18]) 
with 2,048 patients met the predetermined selection criteria and were included in the final study. Seven studies were published in journals $[14-18,23,24]$ and one was a conference abstract [25].

\section{Characteristics of studies and patients}

Table 1 [14-18, 23-25] displays the general characteristics of the included studies. Five studies [14, 16, 17, 23, 24] reported in-hospital outcomes and three studies $[15,18,25]$ reported in-hospital and/or long-term outcomes. Median or mean ages of individuals in the study population ranged from 42 to 57 years. Mean NOS score was 7 (Supplementary Table 2) (www. cardiologyres.org).

As shown in Table 2 [14-18, 23-25], all studies used urine toxicology results to assess recent cocaine use. MI (or myocardial necrosis) was defined based on elevated serum troponin levels or changes in electrocardiogram. Among studies that specified types of BB, $\beta$-selective agents (metoprolol, propranolol, or atenolol) were predominantly used, with the exception of one study in which carvedilol was used in all patients [25]. To investigate in-hospital outcomes, studies included patients who were given BB during their hospital stay or in the ED. For long-term outcomes, studies identified patients who were discharged with BB.

\section{Meta-analysis}

Among patients who presented with cocaine-associated chest pain or recent cocaine use, there was no significant difference in in-hospital all-cause mortality (RR, 0.59; 95\% CI, 0.24 $1.47 ; \mathrm{I}^{2}=0.0 \%$ ) and $\mathrm{MI}$ or myocardial necrosis (RR, 1.24; $95 \% \mathrm{CI}, 0.74-2.06 ; \mathrm{I}^{2}=63 \%$ ) between patients who received BB treatment during the hospital stay and those who did not receive it (Fig. 2). During long-term follow-up (mean 2.6 years), there was no significant difference in all-cause mortality (RR, $0.79 ; 95 \%$ CI, $\left.0.44-1.41 ; \mathrm{I}^{2}=26.6 \%\right)$ and $\mathrm{MI}(\mathrm{RR}, 0.96 ; 95 \%$ CI, $0.40-2.33 ; \mathrm{I}^{2}=0.0 \%$ ) between the two groups (Fig. 3 ).

\section{Publication bias}

Egger's test did not reveal any evidence of small-study effects on all outcomes, but the number of studies was too small to appropriately assess for publication bias $(\mathrm{P}=0.201$ for in-hospital mortality, 0.580 for in-hospital MI/myocardial necrosis, and 0.737 for long-term mortality). Egger's test could not be performed for long-term MI as there were only two studies.

\section{Discussion}

In this meta-analysis, $\mathrm{BB}$ treatment in patients presenting with cocaine-associated chest pain or recent cocaine use was not associated with adverse events. More specifically, there was no difference in $\mathrm{MI} / \mathrm{myocardial}$ necrosis and death during hospital

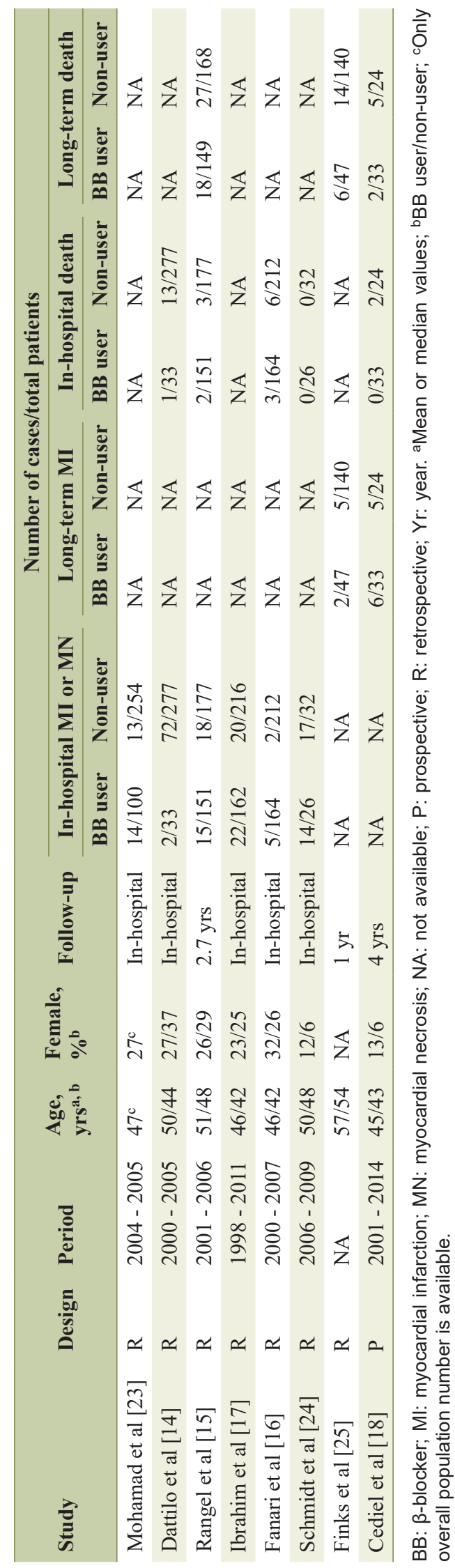


Table 2. Definitions, Types of $\beta$-Blocker, and Timing of Administration

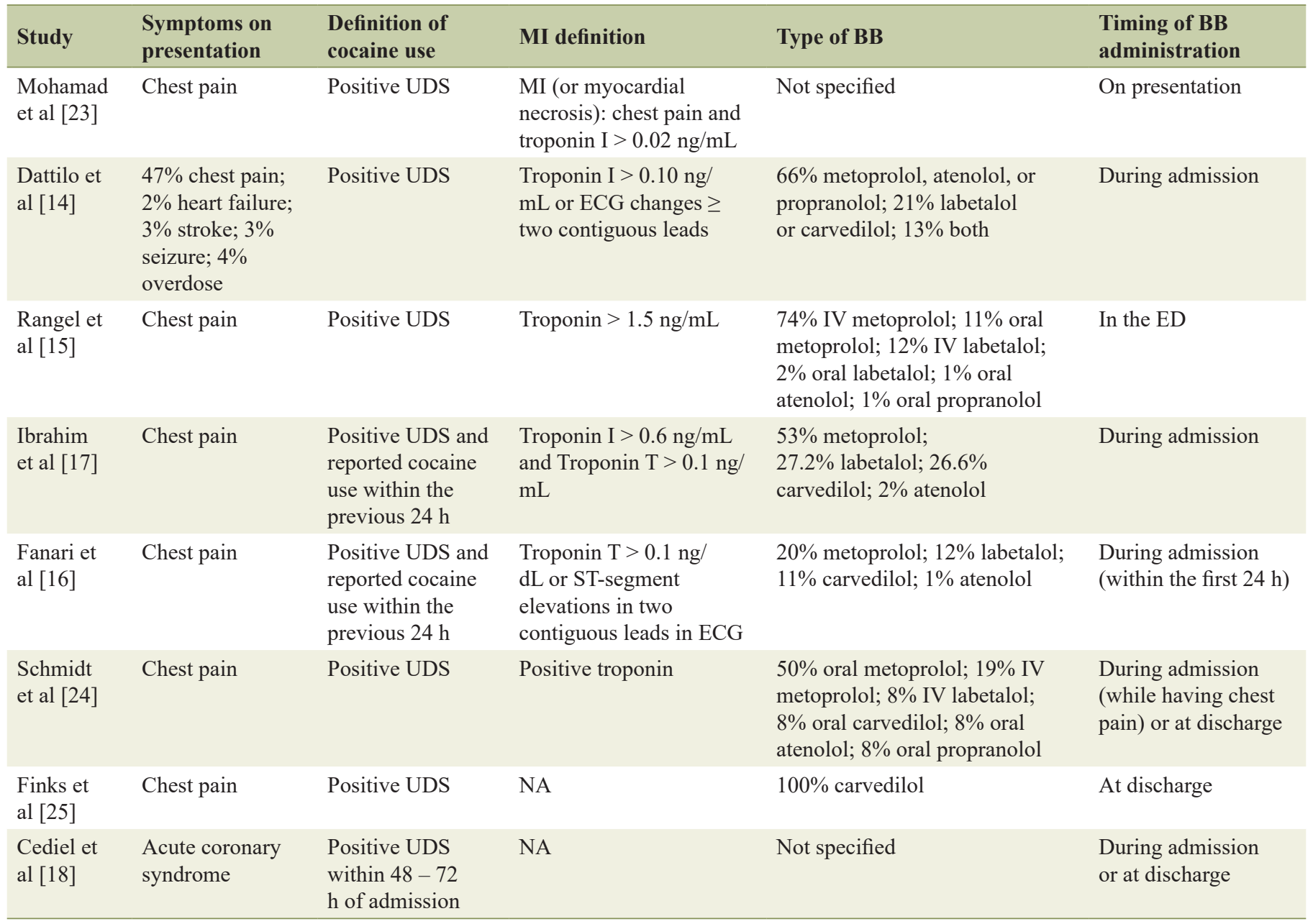

BB: $\beta$-blocker; ECG: electrocardiogram; ED: emergency department; NA: not available; MI: myocardial infarction; UDS: urine drug screening; IV: intravenous.

stays and long-term follow-up between patients who did and did not receive $\mathrm{BB}$ treatment. These results are generally consistent with those reported in the recent meta-analyses [26, 27], but our study is unique in that we included more studies than the prior meta-analyses and differentiated between in-hospital and long-term outcomes for the first time.

Cocaine induces cardiovascular toxicity through various mechanisms. First, it stimulates the sympathetic nervous system by increasing central sympathetic outflow [28] and blocking reuptake of catecholamines at the presynaptic adrenergic terminal $[7,10]$. By doing so, it increases blood pressure, heart rate, and myocardial contractility, and thereby increases myocardial oxygen demand. At the same time, cocaine stimulates coronary vasoconstriction resulting in a decrease in myocardial oxygen supply. Worsening mismatch between myocardial oxygen demand and supply leads to ischemia or infarction. Second, like a class I antiarrhythmic agent, cocaine can cause electrocardiographic changes and induce arrhythmia by blocking sodium and potassium channels [10, 29]. Third, cocaine induces a prothrombotic state by activating platelets and altering the balance between procoagulant and anticoagulant factors [3].

In cocaine users, blocking $\beta$-receptors can leave $\alpha$-stimulation unopposed, potentiating cocaine-induced systemic and coronary vasoconstriction [10]. This theory is largely based on animal studies and case reports/series [1]. However, some have suggested that the outcomes of these case reports/ series may simply be due to the myriad harmful pharmacologic effects of cocaine alone rather than unopposed $\alpha$-stimulation [2]. There have been two small prospective studies, but only 19 patients received intracoronary/intravenous BB in total [30, $31]$. Given the limited evidence, unopposed $\alpha$-stimulation and its clinical significance are still controversial.

Because of the above-mentioned concerns, current guidelines recommend against use of BB in ACS patients with signs of acute cocaine intoxication, unless patients are receiving a coronary vasodilator (class III recommendation: Harm) [9]. In our study, BB treatment in patients presenting with cocaineassociated chest pain or recent cocaine use did not experience an increase in adverse events during their hospital stays. Since many of the included studies did not precisely specify the tim- 


\section{A. In-hospital all-cause death}

\begin{tabular}{|c|c|c|c|c|}
\hline Study & $\mathrm{RR}(95 \% \mathrm{Cl})$ & Treatment & Control & *Weight \\
\hline Dattilo 2008 & $0.65(0.09,4.78)$ & $1 / 33$ & $13 / 277$ & 20.62 \\
\hline Rangel 2010 & $0.78(0.13,4.62)$ & $2 / 151$ & $3 / 177$ & 26.19 \\
\hline Fanari 2014 & $0.65(0.16,2.55)$ & $3 / 164$ & $6 / 212$ & 43.96 \\
\hline Cediel 2018 & $0.15(0.01,2.93)$ & $0 / 33$ & $2 / 24$ & 9.23 \\
\hline Schmidt 2015 & (Excluded) & $0 / 26$ & $0 / 32$ & 0.00 \\
\hline Overall $(\mathrm{l}$-squared $=0.0 \%, p=0.812)$ & $0.59(0.24,1.47)$ & $6 / 407$ & $24 / 722$ & 100.00 \\
\hline
\end{tabular}

\section{B. In-hospital myocardial infarction (or necrosis)}

\begin{tabular}{|c|c|c|c|c|}
\hline Study & $\mathrm{RR}(95 \% \mathrm{Cl})$ & Treatment & Control & *Weight \\
\hline Mohamad 2008 & $2.74(1.33,5.61)$ & $14 / 100$ & $13 / 254$ & 18.54 \\
\hline Dattilo 2008 & $0.23(0.06,0.91)$ & $2 / 33$ & $72 / 277$ & 9.52 \\
\hline Rangel 2010 & $0.98(0.51,1.87)$ & $15 / 151$ & $18 / 177$ & 19.87 \\
\hline Ibrahim 2013 & $1.47(0.83,2.59)$ & $22 / 162$ & $20 / 216$ & 21.47 \\
\hline Fanari 2014 & $3.23(0.64,16.45)$ & $5 / 164$ & $2 / 212$ & 7.36 \\
\hline Schmidt 2015 & $1.01(0.63,1.64)$ & $14 / 26$ & $17 / 32$ & 23.24 \\
\hline Overall $(1-$ squared $=63.0 \%, p=0.019)$ & $1.24(0.74,2.06)$ & $72 / 636$ & $142 / 1168$ & 100.00 \\
\hline
\end{tabular}

Figure 2. In-hospital all-cause death and myocardial infarction (MI) (or myocardial necrosis) in patients with cocaine-associated chest pain who did and did not received beta-blocker treatment. BB: beta-blocker; RR: relative risk; Cl: confidence interval. *Weights are from random effects analysis.

ing of BB administration, we were unable to further investigate the impact of this timing on clinical outcomes. However, many patients in the included studies may have been given BB in the presence of signs of acute intoxication, because BB is typically used for hypertension and tachycardia, which are manifestations of acute cocaine intoxication. Furthermore, the subgroup analysis described in the study by Rangel et al identified no significant differences in electrocardiographic changes, troponin levels, ventricular arrhythmia, or death between patients who received $\mathrm{BB}$ within $6 \mathrm{~h}$ of presentation and those who did not receive $\mathrm{BB}[15]$. Another study reported that administration of $\mathrm{BB}$ within the first $24 \mathrm{~h}$ of presentation did not increase

\section{A. Long-term all-cause death}

\begin{tabular}{|c|c|c|c|c|}
\hline Study & $\mathrm{RR}(95 \% \mathrm{Cl})$ & Treatment & Control & "Weight \\
\hline Rangel 2010 & $0.75(0.43,1.31)$ & $18 / 149$ & $27 / 168$ & 56.37 \\
\hline Finks 2015 & $1.28(0.52,3.13)$ & $6 / 47$ & $14 / 140$ & 30.99 \\
\hline Overall (I-squared $=26.6 \%, p=0.256$ ) & $0.79(0.44,1.41)$ & $26 / 229$ & $46 / 332$ & 100.00 \\
\hline
\end{tabular}

\section{B. Long-term myocardial infarction}

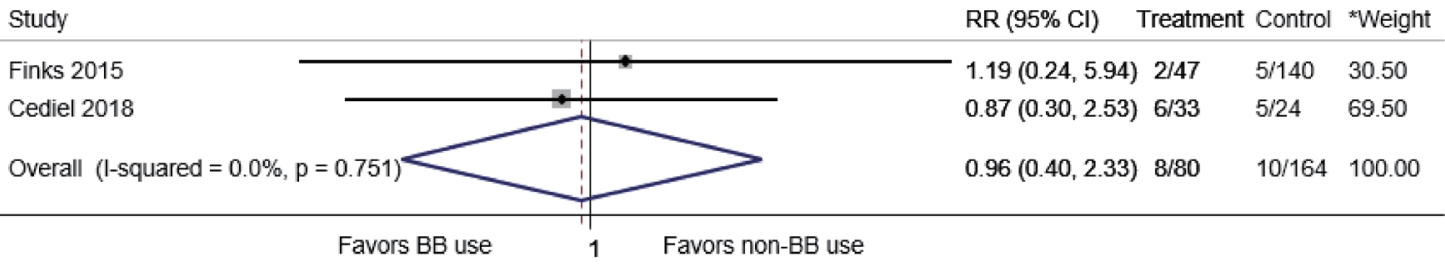

Figure 3. Long-term all-cause death and myocardial infarction (MI) in patients with cocaine-associated chest pain or recent cocaine use who did and did not received beta-blocker treatment. BB: beta-blocker; RR: relative risk; Cl: confidence interval. ${ }^{*}$ Weights are from random effects analysis. 
death, stroke, MI, and arrhythmia [16]. Based on these results, early use of BB during the acute stages of cocaine intoxication may not be as harmful as previously believed. Therefore, $\mathrm{BB}$ may be an effective treatment option, especially for concomitant hypertension and tachycardia secondary to cocaine intoxication, if other options are not working well $[2,13]$. As there has been lack of quality evidence, additional studies are needed to investigate risks and benefits of $\mathrm{BB}$ treatment in cocaine-associated cardiovascular toxicity.

Long-term use of $\mathrm{BB}$ in active cocaine users is also a controversial topic. BB is one of the medicines proven to improve survival in patients after ACS or with heart failure with reduced rejection fraction (HFrEF) $[9,32]$. However, due to concerns regarding unopposed $\alpha$-receptor stimulation, cocaine users were less likely to be prescribed with BB after ACS [33, 34]. In our study, there was no difference in long-term mortality and risk of MI between patients who did and did not receive $\mathrm{BB}$ treatment. In individual studies, patients discharged on $\mathrm{BB}$ exhibited a significant reduction in cardiovascular death [15] and a higher 90-day survival [18]. Among patients with HFrEF and concurrent cocaine use, BB treatment was associated with a reduced 30-day heart failure-related readmission rate [35] and improvement in functional class and left ventricular ejection fraction at a 12-month follow-up without any major adverse cardiovascular event [36]. These results suggest that more studies are needed to investigate risks and benefits of long-term BB treatment in cocaine users.

Another important question is what type of $\mathrm{BB}$ can be used in patients with acute cocaine intoxication. As a major concern is unopposed $\alpha$-stimulation, which can aggravate vasoconstriction, use of combined $\alpha$ - and $\beta$-blocking agents, such as labetalol and carvedilol, or concomitant use of vasodilators with BB may offer theoretical advantages in this patient population [10]. According to a recent review article, no study has reported unopposed $\alpha$-stimulation with the use of combined $\alpha$ - and $\beta$-blocking agents [2]. In the focused update of the 2011 American College of Cardiology (ACC)/American Heart Association (AHA) guidelines for unstable angina/non-ST-elevation MI, administration of combined $\alpha$ - and $\beta$-blocking agents was classified as a class IIb recommendation, provided that the patient has received a vasodilator within close temporal proximity [37]. However, there was no such recommendation in the $2014 \mathrm{ACC} / \mathrm{AHA}$ guideline [9]. Interestingly, metoprolol, a $\beta-1$ selective antagonist, was used in most of the studies included in our meta-analysis (Table 2). In the study by Fanari et al, subgroup analysis according to the types of BB revealed that the use of either $\beta-1$ selective antagonists or combined $\alpha$ and $\beta$-blocking agents did not increase in-hospital composite end point of death, stroke, MI, and arrhythmia [16]. However, evidence was limited, as the other studies did not differentiate between combined $\alpha$ - and $\beta$-blocking agents and $\beta$ - 1 selective agents. It should also be noticed that, in the study by Rangel et al, sublingual or continuous nitroglycerin therapy was more frequently used in patients who received $\mathrm{BB}$ treatment than in those who did not [15]. One may argue that concomitant use of nitroglycerine with BB may have mitigated possible unopposed $\alpha$-stimulation. As most of the other studies did not report such information, we could not further investigate this hypothesis. Therefore, more studies are required to examine above-mentioned theoretical benefits of using combined $\alpha$ - and $\beta$-blocking agents versus $\beta$ - 1 selective agents and concomitant use of vasodilators with $\mathrm{BB}$.

Our study has several limitations. First, we were only able to include observational studies, as there has been no randomized controlled trial on this topic. Second, only a small number of studies were available. Third, small-study effects could not be fully excluded. Fourth, we could not perform subgroup analysis on BB types or the timing of BB administration due to lack of information from individual studies. Finally, definitions of MI were variable among the studies.

In conclusion, our results suggest that BB treatment in patients presenting with cocaine-associated chest pain or recent cocaine use was not associated with in-hospital and long-term death or MI. Additional studies are required to better understand the risks and benefits of $\mathrm{BB}$ administration in these patients.

\section{Acknowledgments}

None.

\section{Financial Disclosure}

The author(s) received no financial support for the research, authorship, and/or publication of this article.

\section{Conflict of Interest}

The authors declare that they have no conflict of interest.

\section{References}

1. Finkel JB, Marhefka GD. Rethinking cocaine-associated chest pain and acute coronary syndromes. Mayo Clin Proc. 2011;86(12):1198-1207.

2. Richards JR, Hollander JE, Ramoska EA, Fareed FN, Sand IC, Izquierdo Gomez MM, Lange RA. beta-Blockers, Cocaine, and the Unopposed alpha-Stimulation Phenomenon. J Cardiovasc Pharmacol Ther. 2017;22(3):239249.

3. McCord J, Jneid H, Hollander JE, de Lemos JA, Cercek B, Hsue P, Gibler WB, et al. Management of cocaine-associated chest pain and myocardial infarction: a scientific statement from the American Heart Association Acute Cardiac Care Committee of the Council on Clinical Cardiology. Circulation. 2008;117(14):1897-1907.

4. Brody SL, Slovis CM, Wrenn KD. Cocaine-related medical problems: consecutive series of 233 patients. Am J Med. 1990;88(4):325-331.

5. Hollander JE, Hoffman RS, Gennis P, Fairweather P, DiSano MJ, Schumb DA, Feldman JA, et al. Prospective multicenter evaluation of cocaine-associated chest pain. Cocaine Associated Chest Pain (COCHPA) Study Group. 
Acad Emerg Med. 1994;1(4):330-339.

6. Feldman JA, Fish SS, Beshansky JR, Griffith JL, Woolard RH, Selker HP. Acute cardiac ischemia in patients with cocaine-associated complaints: results of a multicenter trial. Ann Emerg Med. 2000;36(5):469-476.

7. Whitby LG, Hertting G, Axelrod J. Effect of cocaine on the disposition of noradrenaline labelled with tritium. Nature. 1960;187:604-605.

8. Lange RA, Cigarroa RG, Yancy CW, Jr., Willard JE, Popma JJ, Sills MN, McBride W, et al. Cocaine-induced coronary-artery vasoconstriction. N Engl J Med. 1989;321(23):1557-1562.

9. Amsterdam EA, Wenger NK, Brindis RG, Casey DE, Jr., Ganiats TG, Holmes DR, Jr., Jaffe AS, et al. 2014 AHA/ ACC Guideline for the Management of Patients with Non-ST-Elevation Acute Coronary Syndromes: a report of the American College of Cardiology/American Heart Association Task Force on Practice Guidelines. J Am Coll Cardiol. 2014;64(24):e139-e228.

10. Schwartz BG, Rezkalla S, Kloner RA. Cardiovascular effects of cocaine. Circulation. 2010;122(24):2558-2569.

11. Freeman K, Feldman JA. Cocaine, myocardial infarction, and beta-blockers: time to rethink the equation? Ann Emerg Med. 2008;51(2):130-134.

12. Gupta AK, Greller HA, Hoffman RS. Beta-blockers and cocaine: still a bad idea. Arch Intern Med. 2010;170(20):1859-1860; author reply 1860.

13. Richards JR, Garber D, Laurin EG, Albertson TE, Derlet RW, Amsterdam EA, Olson KR, et al. Treatment of cocaine cardiovascular toxicity: a systematic review. Clin Toxicol (Phila). 2016;54(5):345-364.

14. Dattilo PB, Hailpern SM, Fearon K, Sohal D, Nordin C. Beta-blockers are associated with reduced risk of myocardial infarction after cocaine use. Ann Emerg Med. 2008;51(2):117-125.

15. Rangel C, Shu RG, Lazar LD, Vittinghoff E, Hsue PY, Marcus GM. Beta-blockers for chest pain associated with recent cocaine use. Arch Intern Med. 2010;170(10):874879.

16. Fanari Z, Kennedy KK, Lim MJ, Laddu AA, Stolker JM. Comparison of in-hospital outcomes for beta-blocker use versus non-beta blocker use in patients presenting with cocaine-associated chest pain. Am J Cardiol. 2014;113(11):1802-1806.

17. Ibrahim M, Maselli DJ, Hasan R, Hamilton A. Safety of beta-blockers in the acute management of cocaine-associated chest pain. Am J Emerg Med. 2013;31(3):613-616.

18. Cediel G, Carrillo X, Garcia-Garcia C, Rueda F, Oliveras T, Labata C, Serra J, et al. beta-Blocker treatment and prognosis in acute coronary syndrome associated with cocaine consumption: The RUTI-Cocaine Study. Int J Cardiol. 2018;260:7-10.

19. Wells G SB, O'Connell D, Peterson J, Welch V, Losos M, Tugwell P. The newcastle-ottawa scale (NOS) for assessing the quality of nonrandomised studies in metaanalyses. Ottawa (ON); 2011. Available from http://www. ohri.ca/programs/clinical_epidemiology/oxford.asp. Accessed 20 May 2018.

20. DerSimonian R, Laird N. Meta-analysis in clinical trials.
Control Clin Trials. 1986;7(3):177-188.

21. Higgins JP, Thompson SG, Deeks JJ, Altman DG. Measuring inconsistency in meta-analyses. BMJ. 2003;327(7414):557-560.

22. Egger M, Davey Smith G, Schneider M, Minder C. Bias in meta-analysis detected by a simple, graphical test. BMJ. 1997;315(7109):629-634.

23. Mohamad T, Kondur A, Vaitkevicius P, Bachour K, Thatai D, Afonso L. Cocaine-induced chest pain and beta-blockade: an inner city experience. Am J Ther. 2008;15(6):531535.

24. Espana Schmidt C, Pastori L, Pekler G, Visco F, Mushiyev S. Early use of beta blockers in patients with cocaine associated chest pain. Int J Cardiol Heart Vasc. 2015;8:167169.

25. Finks SW, Brenner M, Kemp DW, Odum L, Parker MH, Parker RB, Rogers KC. Effects of carvedilol in patients after cocaine-induced chest pain. Pharmacotherapy. 2015;35(11):e179.

26. Pham D, Addison D, Kayani W, Misra A, Jneid H, Resar J, Lakkis N, et al. Outcomes of beta blocker use in cocaine-associated chest pain: a meta-analysis. Emerg Med J. 2018;35(9):559-563.

27. Lo KB, Virk HUH, Lakhter V, Ram P, Gongora C, Pressman G, Figueredo V. Clinical outcomes after treatment of cocaine-induced chest pain with beta-blockers: a systematic review and meta-analysis. Am J Med. 2018.

28. Vongpatanasin W, Mansour Y, Chavoshan B, Arbique D, Victor RG. Cocaine stimulates the human cardiovascular system via a central mechanism of action. Circulation. 1999;100(5):497-502.

29. Przywara DA, Dambach GE. Direct actions of cocaine on cardiac cellular electrical activity. Circ Res. 1989;65(1):185-192.

30. Lange RA, Cigarroa RG, Flores ED, McBride W, Kim AS, Wells PJ, Bedotto JB, et al. Potentiation of cocaineinduced coronary vasoconstriction by beta-adrenergic blockade. Ann Intern Med. 1990;112(12):897-903.

31. Boehrer JD, Moliterno DJ, Willard JE, Hillis LD, Lange RA. Influence of labetalol on cocaine-induced coronary vasoconstriction in humans. Am J Med. 1993;94(6):608610.

32. Yancy CW, Jessup M, Bozkurt B, Butler J, Casey DE, Jr., Colvin MM, Drazner MH, et al. 2017 ACC/AHA/ HFSA Focused Update of the 2013 ACCF/AHA Guideline for the Management of Heart Failure: A Report of the American College of Cardiology/American Heart Association Task Force on Clinical Practice Guidelines and the Heart Failure Society of America. Circulation. 2017;136(6):e137-e161.

33. Gupta N, Washam JB, Mountantonakis SE, Li S, Roe MT, de Lemos JA, Arora R. Characteristics, management, and outcomes of cocaine-positive patients with acute coronary syndrome (from the National Cardiovascular Data Registry). Am J Cardiol. 2014;113(5):749-756.

34. DeFilippis EM, Singh A, Divakaran S, Gupta A, Collins BL, Biery D, Qamar A, et al. Cocaine and marijuana use among young adults with myocardial infarction. J Am Coll Cardiol. 2018;71(22):2540-2551. 
35. Egbuche O, Ekechukwu I, Effoe V, Maduabum N, Millard HR, Maihemuti A, Cross JA, et al. Effect of betablocker therapy on hospital readmission and mortality in heart failure patients with concurrent cocaine use. J Cardiovasc Pharmacol Ther. 2018;23(6):518-523.

36. Lopez PD, Akinlonu A, Mene-Afejuku TO, Dumancas C, Saeed M, Cativo EH, Visco F, et al. Improvement in clinical outcomes of patients with heart failure and active cocaine use after beta-blocker therapy. Clin Cardiol.
2018;41(4):465-469

37. Anderson JL, Adams CD, Antman EM, Bridges CR, Califf RM, Casey DE, Jr., Chavey WE, 2nd, et al. 2012 ACCF/ AHA focused update incorporated into the ACCF/AHA 2007 guidelines for the management of patients with unstable angina/non-ST-elevation myocardial infarction: a report of the American College of Cardiology Foundation/American Heart Association Task Force on Practice Guidelines. Circulation. 2013;127(23):e663-828. 